7. Bychkov S., Dolgal A., Simanov A. Interpretation of gravity monitoring data on geotechnical impact on the geological environment // Pure and applied geophysics. - 2021. - V. 178, № 1. - P. 107-121. - DOI: $10.1007 / \mathrm{s} 00024-020-02640-8$.

\title{
ПЛОТНОСТНОЕ СТРОЕНИЕ ВЕРХНЕЙ ЧАСТИ ГЕОЛОГИЧЕСКОГО РАЗРЕЗА НА ВОСТОКЕ ЛЕГЧИМСКОГО СТРУКТУРНОГО ВЫСТУПА
}

\author{
Г.П. Щербинина \\ Горный институт УрО РАН, г. Пермь
}

\begin{abstract}
Аннотация: Гравиметрический метод геофизики применяется на Верхнекамском месторождении калийных солей с 1986 года. Целью данного метода является выявление ослабленных разуплотненных участков в горном массиве, наличие которых необходимо учитывать при разработке месторождения для предотвращения аварийных ситуаций. На территории Легчимского выступа кровли соляной толщи, расположенного в восточной части Предуральского прогиба, была проведена гравиметрическая съемка, в результате которой на изучаемом участке выявлено около двух десятков разуплотненных зон. По приуроченности разуплотнений к разным эффективным (расчетным) глубинам проведена их классификация.

Ключевые слова: Верхнекамское месторождение калийных солей, гравиразведка, надсолевые отложения.
\end{abstract}

Одна из целей проведения гравиметрических работ на Верхнекамском месторождении - подготовка новых площадей к проведению работ по добыче полезного ископаемого $[1,2]$. Изученный гравиметрией участок расположен на северо-востоке территории Четвертого Березниковского калийного рудоуправления в восточной части Легчимского структурного выступа кровли соляной толщи (рис. 1). В 300-600 м севернее изучаемого участка находится южная граница Дуринской системы впадин.

Бурением участок практически не изучен, на момент проведения гравиметрических работ в пределах площади съемки была пробурена одна солеразведочная скв. № 1112 .

Особенностью данной территории является близкое к земной поверхности залегание кровли соляного массива - на глубине 170-220 м. Описание керна скв. 1112 и соседних с участком скважин говорит о выветрелом состоянии надсоляной толщи до дезинтеграции отдельных слоёв. О влиянии агентов выветривания на бо́льшей глубине, в зоне соляной толщи, свидетельствует пёстросильвинитовый состав карналлитовой зоны в скв. 524, расположенной недалеко от восточной границы участка (рис. 1). В скв. 552 (у северной границы площади исследований) отсутствуют покровная и продуктивная толщи и переходная пачка залегает на подстилающей соли.

Таким образом, геологические данные говорят о том, что на изучаемой площади надсоляная и соляная толщи должны иметь неоднородное плотностное строение, с участками выветрелых разуплотненных пород. В гравитационном поле такие участки будут отражаться локальными отрицательными аномалиями.

Подготовка территории к разработке проводилась с целью выявления разуплотненных зон в водозащитной толще, которые априори представляют участки с ослабленными механическими и прочностными свойствами. Для учета их влияния на состояние подработанного массива в процессе проведения горных работ была проведена детальная гравиметрическая съемка масштаба 1:10 000 с плотной сетью пунктов наблюдения $(50 \times 200$ м). Измерение поля силы тяжести осуществлялось современными высокоточ- 
ными приборами фирмы SCINTREX. Среднеквадратическая погрешность определения аномалий Буге составила \pm 0.022 мГал.

Обработка и интерпретация наблюдённых данных проводилась с использованием программы VECTOR [2, 3]. Данная программа позволяет локализовать источники аномалий в координатах изучаемого пространства без наличия априорной информации о плотностном строении территории.

Общая морфология гравитационного поля в редукции Буге, измеренного на изученной площади, отражает поднятие кровли соляной толщи в восточном направлении. Наблюдается общее уменьшение значений на восток. Это объясняется тем, что соляные породы, имеющие значительно меньшую плотность $(2.0-2.2$ г/см³ $)$, чем надсоляные

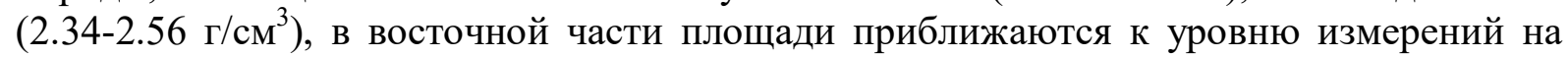
земной поверхности.

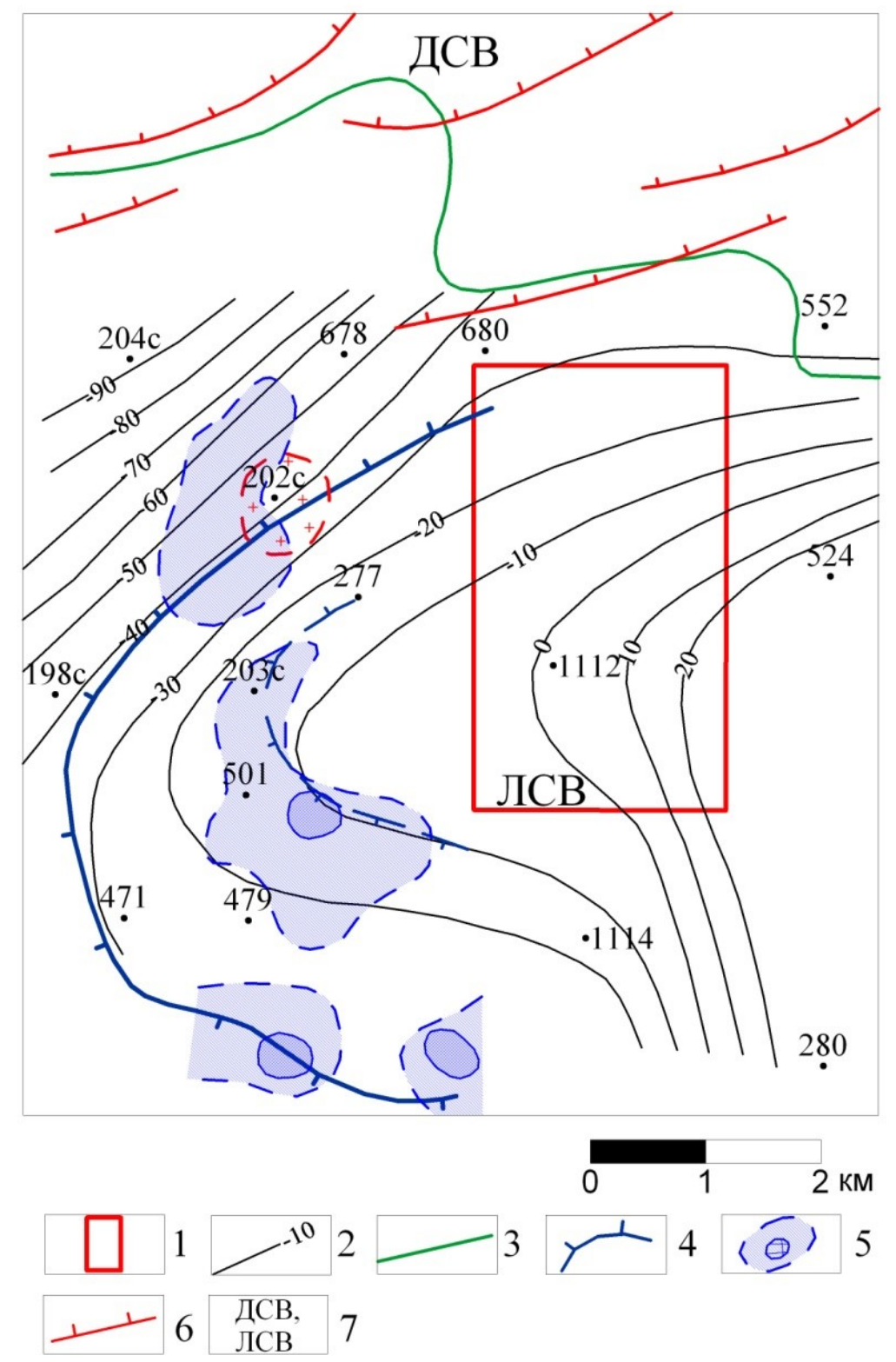

Рис. 1. Геологическая ситуация в районе изучаемого участка: 1 - изучаемый участок; 2 - изогипсы кровли покровной каменной соли; 3 - граница распространения калийных солей; 4 - положительная морфоструктура; 5 - участки с повышенной морфотрещиноватостью; 6 - листрические сбросы в соляном и надсоляном интервале разреза по данным гравиметрии; 7 - структуры соляной поверхности: ДСВ - Дуринская система впадин; ЛСВ - Легчимский структурный выступ 
Обработка измеренных значений поля силы тяжести позволила выявить разуплотненные области и привязать их в пространстве изучаемого горного массива. В результате было выявлено около двух десятков разуплотненных участков, которые можно разделить на четыре типа.

Первый тип - это разуплотнения, проявляющиеся отрицательными объемными аномалиями значительной амплитуды, которые распространяются на эффективных глубинах, соответствующих глубинам залегания подстилающей соли, продуктивной толщи и постепенно затухают на глубинах надсоляной толщи. Точки локализации данных аномалий фиксируются в пределах эффективных глубин подстилающей соли 400-500 м. Амплитуда аномалий на эффективной глубине, соответствующей водозащитной толще, составляет 0.03-0.04 мГал. Горизонтальные размеры аномалий 700-800 м. Это аномалии 10 и 17 на рис. 2.

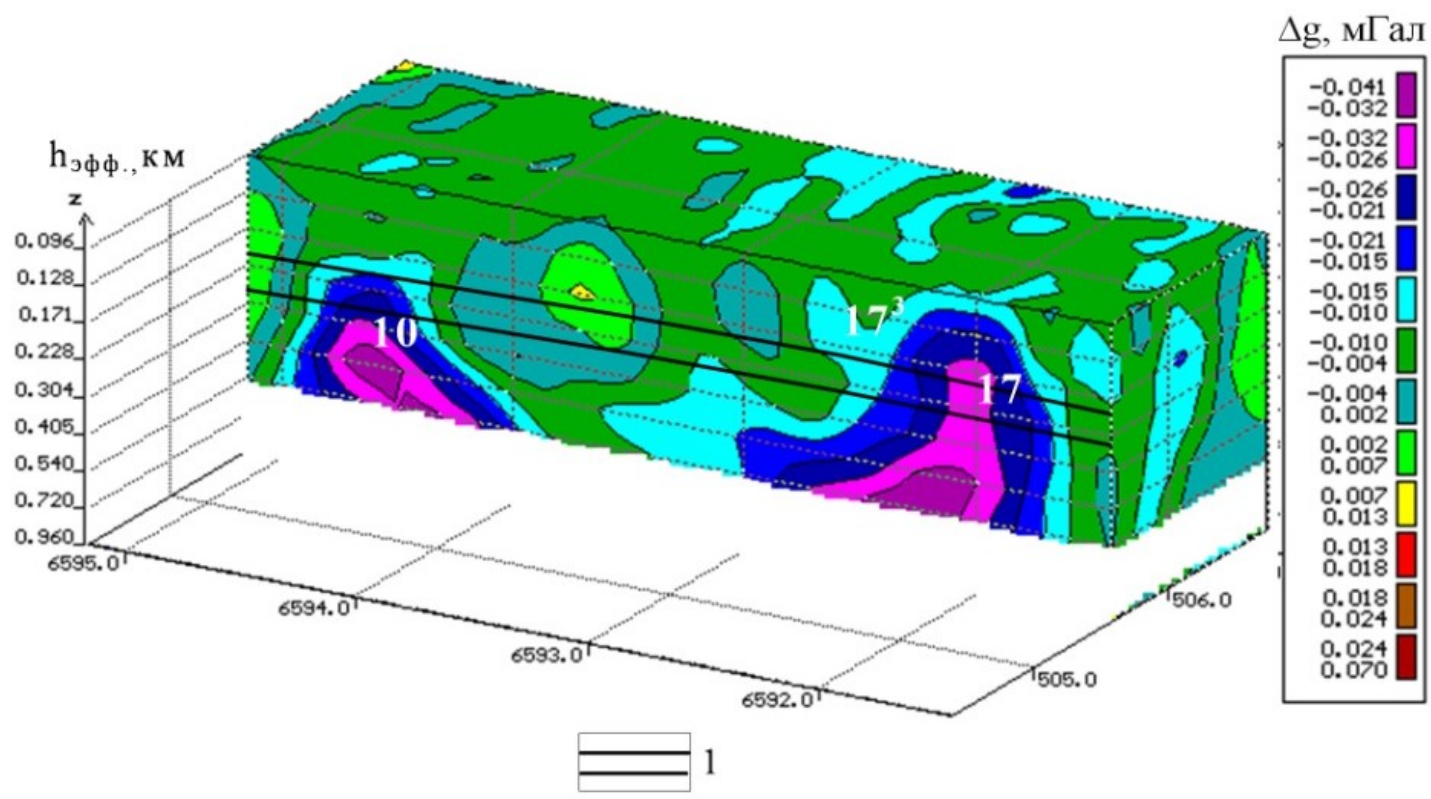

Рис. 2. Отрицательные аномалии первого типа (№ 10, 17): 1 - положение кровли покровной соли и кровли подстилающей соли, привязанные к эффективным глубинам трансформанты

Разуплотнения второго типа характеризуются аномалиями значительно меньшей амплитуды (0.02-0.03 мГал) и меньших горизонтальных размеров (около 500 м), сквозными через весь разрез. Такие аномалии $(№ 16,18)$ выявлены на восточной границе участка. Вертикальное сечение трехмерной трансформанты поля через аномалии № 16, 18 приведено на рис. 3.

К третьему типу отнесены разуплотнения, проявляющиеся аномалиями небольшой амплитуды (0.01-0.02 мГал), которые локализуются на эффективных глубинах, соответствующих надсоляной толще и кровле соли. Глубина локализации 170-200 м. Горизонтальные размеры аномалий 300-400 м. Обнаружено шесть таких аномалий. Разуплотнения этого типа выявлены на вершине структурного выступа соляной поверхности. Вертикальные сечения через аномалии данного типа № 14 и 15 показаны на рис. 4.

К четвертому типу отнесены разуплотненные области, выраженные аномалиями, проявляющимися на эффективных глубинах, характерных для глубин залегания надсоляной толщи. Аномалии характеризуются слабой интенсивностью (около 0.01 мГал) и небольшими горизонтальными размерами (250-300 м). В качестве примера приведено сечение трехмерной трансформанты через аномалию № 34 (рис. 5). 


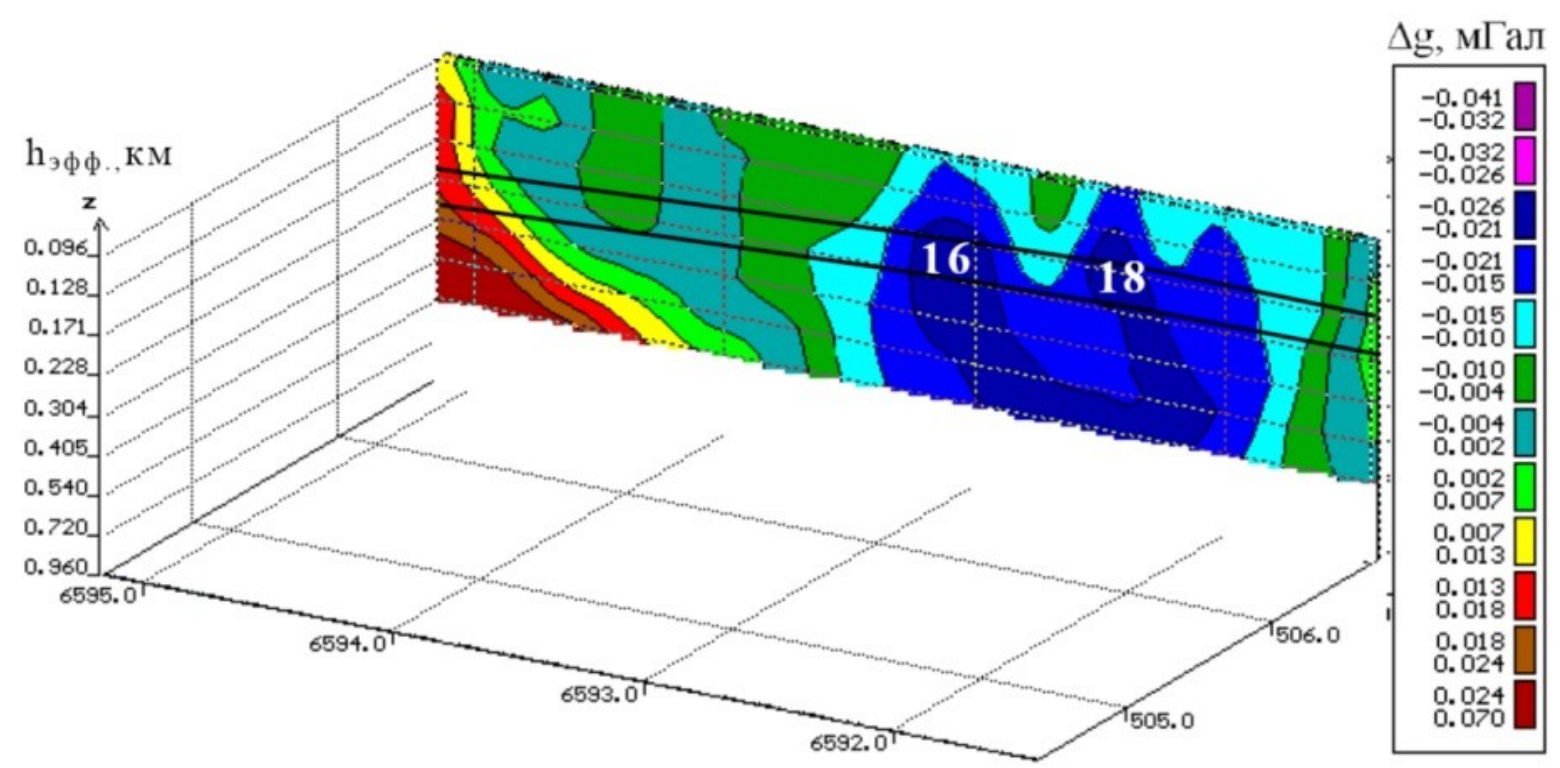

Рис. 3. Отрицательные аномалии второго типа (№ 16, 18)

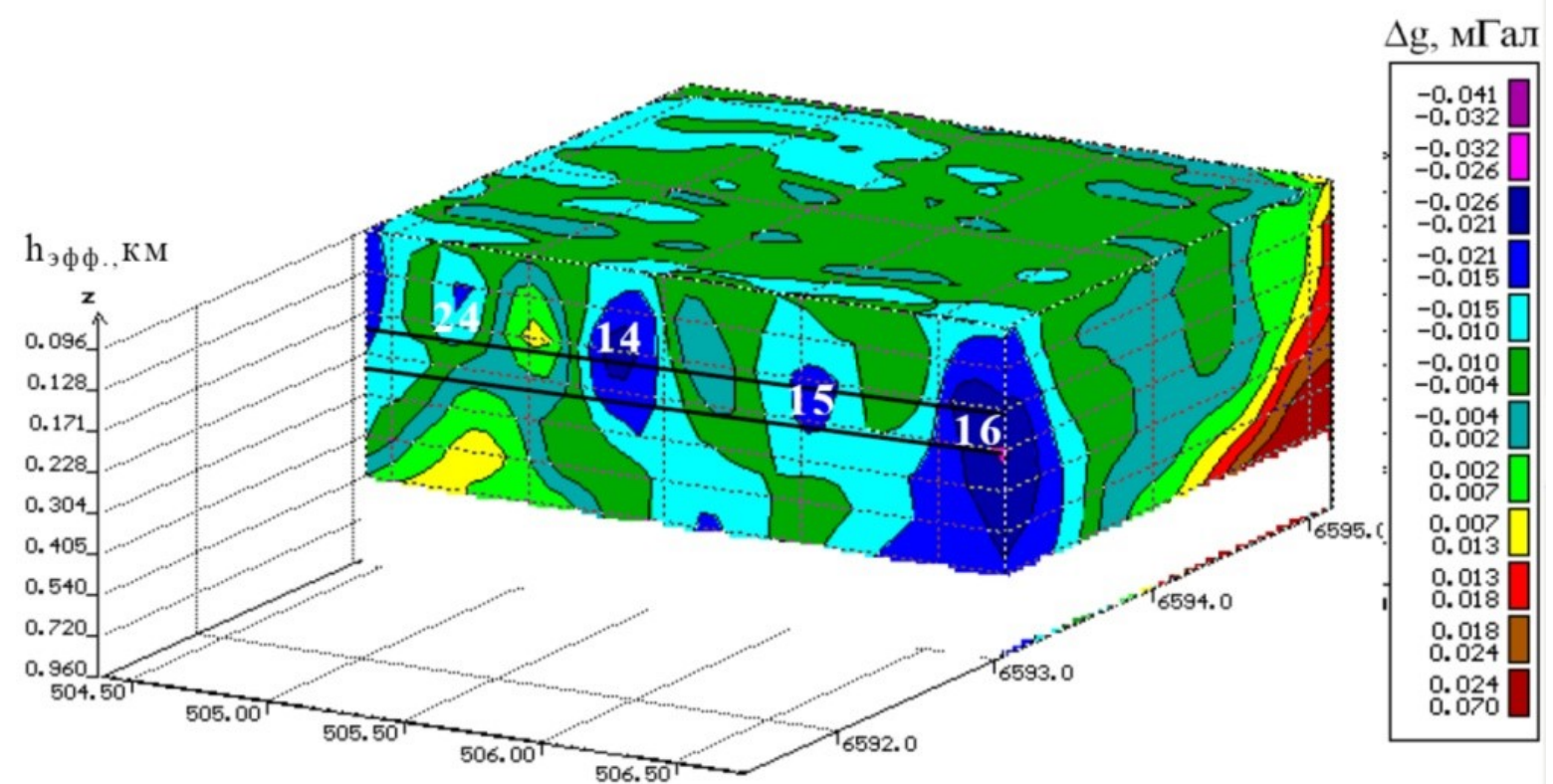

Рис. 4. Отрицательные аномалии третьего типа (№ 14, 15)

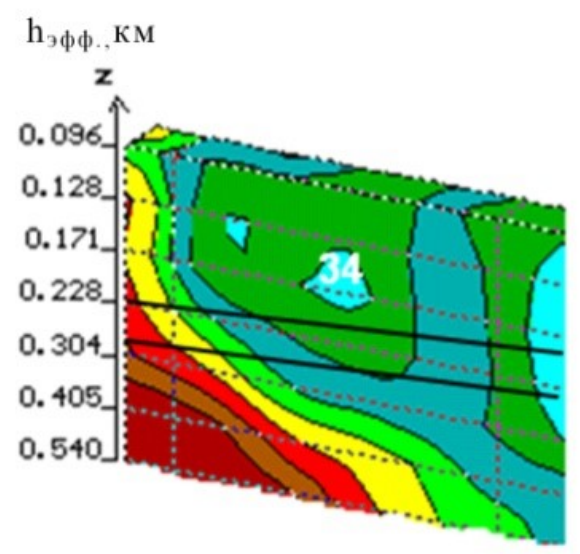

Рис. 5. Отрицательные аномалии четвертого типа (№ 34) 
После проведения анализа характеристик отрицательных гравитационных аномалий амплитуд, глубин локализации, горизонтальных размеров и интервалов проявления были выделены наиболее проблемные при проведении горных работ участки. Это районы аномалий первой группы.

Работа выполнена при поддержке РФФИ (проект № 19-45-590011р_а).

\title{
БИБЛИОГРАФИЧЕСКИЙ СПИСОК
}

1. Бычков С.Г., Простолупов Г.В., Щербинина Г.П. Гравиметрические исследования Верхнекамского месторождения калийных солей / С.Г. Бычков, Г.В. Простолупов, Г.П. Щербинина // Геофизика. 2014. - №5. - C. 46-51.

2. Щербинина Г.П. Высокоточная гравиметрия при обеспечении безопасной отработки Верхнекамского месторождения калийных солей / Г.П. Щербинина, Г.В. Простолупов // Горный информационно-аналитический бюллетень (научно-технический журнал). - 2015. - № 3 . С. 219-226.

3. Новоселицкий В.М., Чадаев М.С., Погадаев С.В. Векторное сканирование потенциальных полей инструмент глубинных исследований // Горные науки на рубеже XXI века (Мельниковские чтения): тез. докл. Междунар. конф. / ГИ УрО РАН [и др.]. - Пермь, 1997. - С. 147-148.

4. Простолупов Г.В., Новоселицкий В.М., Конешов В.Н., Щербинина Г.П. Об интерпретации гравитационного и магнитного полей на основе трансформации горизонтальных градиентов в системе Vесtor // Физика Земли. - 2006. - № 6 - С. 90-96.

\section{ОБОСНОВАНИЕ СЕЙСМОГЕОЛОГИЧЕСКОЙ МОДЕЛИ ВЫРАБОТАННОГО ПРОСТРАНСТВА ДЛЯ РАЗНОТИПНЫХ ВОЛНОВЫХ ПОЛЕЙ}

\author{
А.Г. Ярославцев \\ Горный институт УрО РАН, г. Пермь
}

\begin{abstract}
Аннотация. На основе конечно-разностного полноволнового моделирования показано влияние выработанного пространства на характеристики направленности разнотипных волн для различных точек приложения сосредоточенной силы к свободной поверхности. Результаты дают возможность более корректно обосновать выбор технологии шахтной сейсморазведки для изучения различных целевых областей вмещающего выработку соляного массива. Выполнен подбор оптимальных характеристик выработанного пространства для получения его реалистичных отображений при 2D моделировании.

Ключевые слова: шахтная сейсморазведка, отраженные волны, полноволновое моделирование, поперечные волны, продольные волны.

Согласно ряду исследований [1-6] при проведении сейсморазведочных работ в условиях шахт и тоннелей на формируемое волновое поле значительное влияние оказывает сама горная выработка, в которой производится возбуждение упругих колебаний. Это связано с тем, что характеристики направленности применяемых точечных источников зависят как от их положения относительно поперечного профиля выработки, так и от направления сосредоточенной силы относительно изучаемой целевой плоскости. Кроме этого, при сейсморазведке во внутренних точках среды следует принимать во внимание, что регистрируемый сигнал является результатом интерференции волн, приходящих из разных областей пространства.
\end{abstract}

